\title{
PERANCANGAN SISTEM INFORMASI BOOKING BUKU BERBASIS WEB PADA PERPUSTAKAAN SMK PANCAKARYA TANGERANG
}

\author{
Triyono ${ }^{1}$ \\ Diah Minarsih $^{2}$ \\ Dwi Oktavia $^{3}$ \\ Dosen STMIK Raharja ${ }^{1}$, STMIK Raharja Jurusan Manajemen Informatika ${ }^{2,3}$ \\ Jl. Jendral Sudirman No. 40 Modern Cikokol Tangerang, 15117, Indonesia. \\ Email: triyono@raharja.info ${ }^{1}$,diah.minarsih@raharja.info ${ }^{2}, \underline{\text { dwi.oktavia@ raharja.info }}{ }^{3}$
}

\begin{abstract}
ABSTRAK
Berdasarkan pengamatan langsung, perpustakaan SMK Pancakarya merupakan perpustakaan yang seluruh aktivitasnya masih bersifat manual dan belum menyediakan fasilitas booking buku untuk para anggota secara online. Hal tersebut mungkin dapat menimbulkan permasalahan dalam memberikan pelayanan kepada para anggota dalam mencari informasi data buku dan melakukan peminjaman buku. Karena sistem yang ada masih manual menyebabkan para anggota kesulitan dalam mencari buku karena terkadang buku yang dicari tidak dapat ditemukan ataupun buku yang ingin di pinjam tidak dapat di pinjam karena sedang di pinjam. Penelitian ini dilakukan untuk merancang suatu sistem informasi perpustakaan berbasis web yang terdapat fasilitas pencarian buku dan booking buku secaraonline sehingga nantinya dapat memudahkan para anggota serta dapat diaplikasikan pada perpustakaan SMK Pancakarya Tangerang.
\end{abstract}

Kata kunci: Perpustakaan, Sistem Informasi, Booking Buku, Online, Peminjaman Buku

\begin{abstract}
Based on direct observation, SMK Pancakarya library is a library whose entire activities are still manual and have not provided book booking facility for members online. It may cause problems in providing services to members in searching information book data and lending books. Because the system is still manual cause the members difficulty in finding the book because sometimes the book sought can not be found or books that want to borrow can not be borrowed because it is on loan. This research was conducted to design a web-based library information system that there is a book search facility and book reservations online so that later can facilitate the membersand can be applied to the library SMK Pancakarya Tangerang.
\end{abstract}

Keyword: Library, Information System, Book Booking, Online, Book Lending

\section{PENDAHULUAN}

Perkembangan teknologi dan ilmu pengetahuan pada masa era globalisasi saat ini dirasakan semakin meningkat terutama dalam bidang pendidikan. Pendidikan dapat mengembangkan pola pikir sehingga masyarakat menjadi lebih maju dan modern dalam mengikuti perkembangan era globalisasi. Wadah yang dapat meningkatkan kualitas masyarakat dalam bidang pendidikan terutama di sekolah yaitu perpustakaan. Dan perpustakaan yang baik yaitu harus meningkatkan kualitasnya dengan menyediakan fasilitas yang memadai, yaitu ruangan yang nyaman, udara yang sejuk dan tata ruangan yang rapi serta ditambah adanya internet gratis (wifi) yang diperuntukan agar siswa/I merasa lebih nyaman ketika berada di perpustakaan. 
Sistem informasi perpustakaan SMK Pancakarya yang berjalan saat ini masih secara manual dalam proses pengolahan datanya dengan menggunakan buku besar. Dan proses pelayanan yang diberikan petugas masih belum maksimal. Sehingga membuat para anggota enggan untuk berkunjung, membaca ataupun meminjam buku di perpustakaan. Dan karena cukup banyaknya buku di perpustakaan, membuat para anggota kesulitan dalam mencari dan mengetahui informasi data buku.Terutama dalam peminjaman buku, anggota harus terlebih dahulu mencari buku yang diinginkan, namun terkandang anggota tidak dapat melakukan peminjaman karena tidak tersedianya stok buku ataupun buku sedang dipinjam anggota lain dan hal tersebut menghambat dan menyia-nyiakan waktu karena hal yang dicari tidak dapat diperoleh. Maka dari itu perpustakaan SMK Pancakarya Tangerang memerlukan suatu sistem yang bersifat komputerisasi guna memudahkan atau membantu para anggota dalam mencari informasi data buku dan untuk melakukan booking buku yang ingin dipinjam dengan cepat dan akurat.

Untuk memenuhi kebutuhan dan mengatasi permasalahan yang ada, perpustakaan SMK Pancakarya Tangerang perlu dikelola dengan baik menggunakan sistem yang sudah terkomputerisasi, dimana sistem yang akan dibuat yaitu sistem informasi booking buku berbasis web yang diharapkan dapat mempermudah siswa/i dalam mendapatkan informasi, melakukan pemesanan/booking buku yang akan dipinjam secara online dimanapun dan kapan pun secara cepat.

Dengan adanya sistem tersebut dapat memudahan anggota dalam melakukan pencarian informasi tentang data buku dan booking buku yang ingin dipinjam melalui sistem informasi booking buku secara online. Dan sistem tersebut juga dapat diakses oleh anggota perpustakaan kapan dan dimana saja melalui komputer ataupun telepon seluler yang terhubung ke internet.

Rumusan permasalahan penelitian yang dapat ditarik adalah, sebagai berikut :

1. Bagaimana sistem informasi pelayanan perpustakaan yang berjalan saat ini pada SMK Pancakarya Tangerang?

2. Apakah proses pelayanan yang ada pada perpustakaan SMK Pancakarya Tangerang sudah sesuai dengan kebutuhan ?

3. Bagaimana merancang suatu sistem informasi perpustakaan berbasis web dan dapat menyediakan layanan online untuk booking buku yang ingin dipinjam pada SMK Pancakarya Tangerang?

\section{TUJUAN PENELITIAN}

Dalam penyusunan laporan penelitian ini didapatkan beberapa tujuan penelitian, sebagai berikut :

1. Untuk mengetahui sistem informasi perpustakaan yang berjalan pada SMK Pancakarya Tangerang.

2. Untuk mengetahui kebutuhan informasi yang terkait dengan proses pelayanan terhadap para anggota pada perpustakaan SMK Pancakarya Tangerang.

3. Untuk merancang sistem informasi booking buku pada perpustakaan berbasis web yang berfungsi untuk melakukan booking buku yang akan dipinjam secara online pada SMK Pancakarya Tangerang. 


\section{MANFAAT PENELITIAN}

Manfaat yang dihasilkan dari penelitian yang dilakukan, diantaranya:

1. Dapat menjadi perpustakaan yang lebih efektif dan efesien dalam memenuhi kebutuhan sistem informasi perpustakaan pada SMK Pancakarya Tangerang.

2. Dapat mempermudah anggota perpustakaan dalam mencari informasi mengenai data buku dan melakukan boking buku yang ingin dipinjam secara online.

\section{LANDASAN TEORI}

\section{Sistem}

Systems: Groups or combinations of interrelated, interdependent, or interacting element forming collective entities.[1]

\section{Sistem Informasi}

Sistem informasi adalah kumpulan dari sub-sub sistem baik phisik maupunnon phisik yang saling berhubungan satu sama lain dan bekerja sama secara harmonis untuk mencapai satu tujuan yaitu mengolah data menjadi informasi yang berguna. [2]

\section{Perancangan Sistem}

Perancangan sistem yaitu merancang/memodelkan sistem secara rinci berdasarkan hasil analisis dari sistem berjalan sehingga menghasilkan model baru yang akan diusulkan disertai dengan rancangan database dan ranangan aplikasi/program. [3]

\section{Booking Buku}

Booking buku disebut juga pemesanan buku yang ingin dipinjam sebelum melakukan peminjaman langsung ke perpustakaan. Misalkan anggota perpustakaan ingin meminjam buku, agar lebih mudah anggota perpustakaan dapat melakukan booking buku terlebih dahulu agar ketika anggota melakukan peminjaman ke perpustakaan buku yang ingin dipinjam ada karena sudah di booking sebelumnya.

\section{Perpustakaan}

Perpustakaan adalah suatu tempat, berupa sebuah ruangan atau gedung yang berisi buku-buku dan bahan lain untuk bacaan, studi, atau pun rujukan.(Random House)[4]

\section{Anggota Perpustakaan}

Anggota perpustakaan SMK Pancakarya Tangerang diantaranya: Siswa/I, Guru, TU, Kepala Sekolah. 


\section{UML (Unified Modelling Language)}

Unified Modelling Language (UML) adalah himpunan struktur dan teknik untuk pemodelan desain program berorientasi objek (OOP) serta aplikasinya. UML adalah metodologi untuk mengembangkan sistem OOP dan sekelompok perangkat tool untuk mendukung pengembangan sistem tersebut.[5]

Unified Modeling Language (UML) adalah keluarga notasi grafis yang didukung oleh metamodel tunggal, yang membantu pendeskripsian dan desain sistem perangkat lunak, khusunya sistem yang dibangun menggunakan pemrograman berorientasi objek. [6]

Use case atau diagram use case menggambarkan kelakukan (behavior) sistem informasi yang akan dibuat. Use case mendeskripsikan sebuah interaksi antar satu atau lebih actor dengan sistem informasi yang akan dibuat. Secara kasar, use case digunakan untuk mengetahui fungsi apa saja yang ada di dalam sebuah sistem informasi dan siapa saja yang berhak menggunakan fungsi-fungsi itu.(Sugiarti)[7]

Use case diagram adalah sesuatu yang penting untuk memvisualisasikan, menspesifikasikan dan mendokumentasikan kebutuhan perilaku sistem.[8]

Class diagram digunakan untuk menggambarkan struktur dalam objek sistem. Diagram ini menunjukkanclass object yang menyusun sistem dan juga hubungan antara class object. (Sugiarti)[7]

Class Diagram merupakan diagram yang menunjukan class-class yang ada di sistem dan hubungannya secara logic. [8]

\section{Website}

Website atau situs dapat diartikan sebagai kumpulan halaman-halaman yang digunakan untuk menampilkan informasi teks, gambar diam atau gerak, animasi, suara, dan atau gabungan dari semuanya baik yang bersifat dinamis yang membentuk datu rangkaian bangunan yang saling terkait, yang masing-masing dihubungkan dengan jaringan-jaringan halaman. Hubungan antara satu halaman web dengan halaman web lainnya disebut hyperlink, sedangkan teks yang dijadikan media penghubung disebut hypertext.[9]

\section{Internet}

Internet singkatan dari international network, internet merupakan jaringan komputer raksasa yang mengintegrasikan ribuan jaringan komputer 200 negara.[2]

\section{PHP}

PHP adalah bahasa script yang ditanam di sisi server. Prosesor PHP dijalankan di server (windows atau linux), saat sebuah halaman dibuka dan mengandung kode PHP, prosesor itu akan menerjemahkan dan mengeksekusi semua perintah dalam halaman tersebut dan menampilkannya ke browser.(Prasetio, 2014)[10] 
HTML

HTML merupakan singkatan dari HyperText Markup Language merupakan bahasa paling dasar dan penting yang digunakan untuk menampilkan dan mengelola tampilan halaman website. HTML juga digunakan untuk menampilkan berbagai informasi di dalam sebuah penjelajah web internet dan formatting hypertext sederhana yang ditulis dalam berkas format ASCII agar dapat menghasilkan tampilan wujud yang terintegrasi.(Saputra, 2012)[10]

\section{CSS}

CSS merupakan singkatan dari Cascading Style Sheet merupakan bahasa pemrograman web yang di desain khusus untuk mengendalikan dan membangun berbagai komponen dalam web sehingga tampilan web lebih rapi, struktur, dan seragam.(Saputra, 2012)[10]

\section{Bootstrap}

Bootstrap merupakan sebuah framework CSS dari twitter, yang menyediakan kumpulan komponen-komponen antarmuka dasar pada web yang telah dirancang sedemikian rupa untuk digunakan bersama-sama.[11]

\section{jQuery}

jQuery adalah suatu library javascript yang akan menjadikan web Anda lebih bagus dalam hal User Interface, lebih stabil, dan dapat mempercepat waktu dan kinerja Anda dalam membuat web karena hanya perlu memanggil fungsinya saja tanpa harus membuat dari awal.[12]

\section{Database}

Database atau basis data didefinisikan sebagai himpunan kelompok data yang saling berhubungan yang diorganisasikan sedemikian rupa agar kelak dapat dimanfaatkan kembali dengan cepat dan mudah.[12]

Database adalah kumpulan informasi yang disimpan dalam komputer secara sistematik untuk memperoleh informasi dari basis data".[13]

\section{METODOLOGI PENELITIAN}

Dalam menyusun laporan penelitian serta merancang suatu sistem, digunakan beberapa metode penelitian untuk mendapatkan data yang diperlukan guna memperoleh hasil yang diharapkan. Berikut metode yang digunakan dalam penelitian ini.

\section{Observasi}

Mendapatkan data dengan metode observasi yaitu melakukan pengamatan langsung terhadap proses pelayanan pada perpustakaan SMK Pancakarya Tangerang. Kemudian dari pengamatan tersebut, didapatkan data yang merupakan sumber informasi penting yang membantu menganalisa dalam merancang sistem informasi booking buku. 


\section{Wawancara}

Metode ini dilakukan dengan cara tanya jawab secara langsung kepada pihak yang bersangkutan dengan objek yang berkaitan tentang sistem informasi perpustakaan SMK Pancakarya Tangerang yang sedang berjalan saat ini, dalam hal ini dilakukan wawancara langsung dengan Bapak Agus Susanto sebagai stakeholder dan Bapak Wiharto Wardono sebagai petugas perpustakaan SMK Pancakarya Tangerang. Dilakukannya metode ini guna memperoleh data yang lebih lengka serta memperkuat data sebelumnya saat melakukan pengamatan secara langsung.

\section{Studi Pustaka}

Studi pustaka dilakukan dengan mencari bahan referensi yang berkaitan atau mendukung dalam penulisan laporan penelitian melalui beberapa sumber (literature) seperti bukubuku, majalah, artikel, karya ilmiah dan internet yang erat kaitannya dengan permasalahan yang ada untuk kebutuhan analisa dan perancangan yang terkait dengan penulisan laporan penelitian ini.

\section{Metode Analisa}

Kegiatan analisa merupakan salah satu langkah penting dalam rangka memperoleh fakta dan informasi hasil penelitian. Data dan informasi harus dianalisis menggunakan metode dan teknik yang tepat. Dalam metode analisa ini menggunakan metode SWOT, dimana metode ini menganalisis faktor-faktor internal dan eksternal yang ditentukan oleh 4 (empat) aspek yaitu Kekuatan/Strength (S), Kelemahan/Weakness (W), Peluang/Opportunities (O), dan Ancaman/Threat (T). Keempat faktor tersebut dibagi lagi menjadi 4 strategi yaitu Strategi S-O (Strength-Opportunities), Strategi W-O (WeaknessOpportunities), Strategi S-T (Strength-Threat), dan terakhir Strategi W-T (WeaknessThreat).

\section{Metode Perancangan}

Pada metode perancangan program yang diusulkan ini, metode yang digunakan yaitu metode perancangan yang berorientasi objek melalui tahap pemodelan Unified Modelling Language (UML). Metode ini yaitu metode dari sistem ke modul yang lebih kecil untuk memudahkan dalam menganalisa, dimanapemodelan diagram UML yang digunakan yaitu use case diagram dan class diagramsebagai rancangan basis data dengan menggunakan alat bantu (tool) berupa Visual Paradigm for UML 6.4 Enterprise Edition.

\section{LITERATURE REVIEW}

\section{Penelitian Yang Dilakukan Oleh Indra Gunawan dan Winda Agustina (2015)}

Penelitian yang telah dilakukan oleh peneliti tersebut berjudul "Perancangan Sistem Informasi Perpustakaan Berbasis Web Pada SMK Swasta Budi Setia". Penelitian ini dilakukan karena adanya permasalahan yang ada pada SMK Swasta Budi Setia, sebagai berikut, sistem yang ada saat ini masih bersifat manual jadi masih sangat banyak memakan waktu dan tidak dapat memberikan informasi yang akurat. Metode penelitian yang digunakan diantaranya: metode 
pengumpulan data yang dilakukan dengan dua cara yaitu studi kepustakaan dan studi lapangan. Metode ini dilakukan guna mendapatkan data dan teori-teori yang berhubungan dengan objek penelitian.Metode perancangan yang dilakukan terdiri dari perancangan use case diagram, class diagram, database, dan site map.Hasil dari penelitian tersebut merancang sistem perpustakaan yang dapat digunakan anggota perpustakaan untuk mendapatkan informasi yang jelas mengenai buku melalui website. Staff perpustakaan dan anggota dapat memperoleh informasi yang dibutuhkan secara cepat dan akurat.

\section{Penelitian Yang Dilakukan Oleh Windha Fransiska Yopie dan Asis Ahmadi (2015)}

Peneliti melakukan penelitian dengan judul "Perancangan Sistem Informasi Peminjaman Buku Pada Perpustakaan SMK Negeri Kebonagung". Alasan dilakukan penelitian tersebut yaitu untuk membangun sistem informasi yang dapat mempermudah pelaksanaan kegiatan di perpustakaan dengan sistem terkomputerisasi secara keseluruhan maupun beberapa bagian dari proses peminjaman buku dan pengembalian buku yang disesuaikan dengan alur yang ditetapkan oleh pihak SMK Negeri Kebonagung. Hasil dari penelitian ini adalah untuk menghasilkan perancangan sistem informasi pengolahan data perpustakaan pada SMK Negeri Kebonagung yang diharapkan dapat memberikan gambaran kepada pihak Sekolah dalam proses pengolahan transaksi peminjaman dan pengembalian buku yang terkomputerisasi. Dari hasil penelitian tersebut didapatkan beberapa saran sebagai berikut: desain sistem tersebut dapat dikembangkan dan dibuat lebih menarik dan lebih mudah dimengerti untuk kedepannya, menggunakan komputer dengan spesifikasi yang bagus.

\section{Penelitian Yang Dilakukan Oleh Evergard Omega Souhoka, Rini Darmastuti, dan Rudy Latuperissa (2013)}

Penelitian ini berjudul Perancangan Sistem Informasi Perpustakaan Daerah Kota Ambon Berbasis Web Online. Pada penelitian ini metode yang digunakan dalam pengembangan sistem adalah Prototype. Proses awal yaitu proses pengumpulan data yang dilakukan dengan mencari informasi mengenai kebutuhan sistem yang akan dibuat dengan cara wawancara dan membaca literature. Tahap kedua dilakukan perancangan sistem dengan menggunakan Unified Modelling Language (UML) dengan menggunakan use case diagram, activity diagram, sequence diagram dan class diagram, dalam tahap ini juga dilakukan desain struktur database yang merupakan tahapan perancangan terhadap database sesuai dengan data-data yang terlibat dengan proses yang terjadi pada modul tersbut. Kemudian dilakukan desain arsitektur sistem yang merupakan tahapan yang terakhir dalam perancangan sistem sesuai dengan requirment sistem yang telah didefinisikan sebelumnya. Tahap terakhir adalah evaluasi prototype dengan melakukan pengujian terhdap aplikasi yang telah dibuat. Perancangan sistem informasi perpustakaan daerah Kota Ambon di bangun untuk mempermudah masyarakat dalam peminjaman buku secara online. Hasil dari perancangan sistem tersebut yaitu sistem informasi perpustakaan daerah kota Ambon berbasis web yang berfungsi sebagai media storage data pustaka. Sistem ini membantu memberikan kemudahan akses data pustaka bagi user, serta memberikan sebuah sistem yang terintegrasi baik secara online dengan menggunakan database. 


\section{HASIL DAN PEMBAHASAN}

\section{Perancangan Sistem}

Dalam perancangan sistem ini menggunakan metode object oriented denganUML (Unified Modelling Language) dengan bantuan use case diagram.

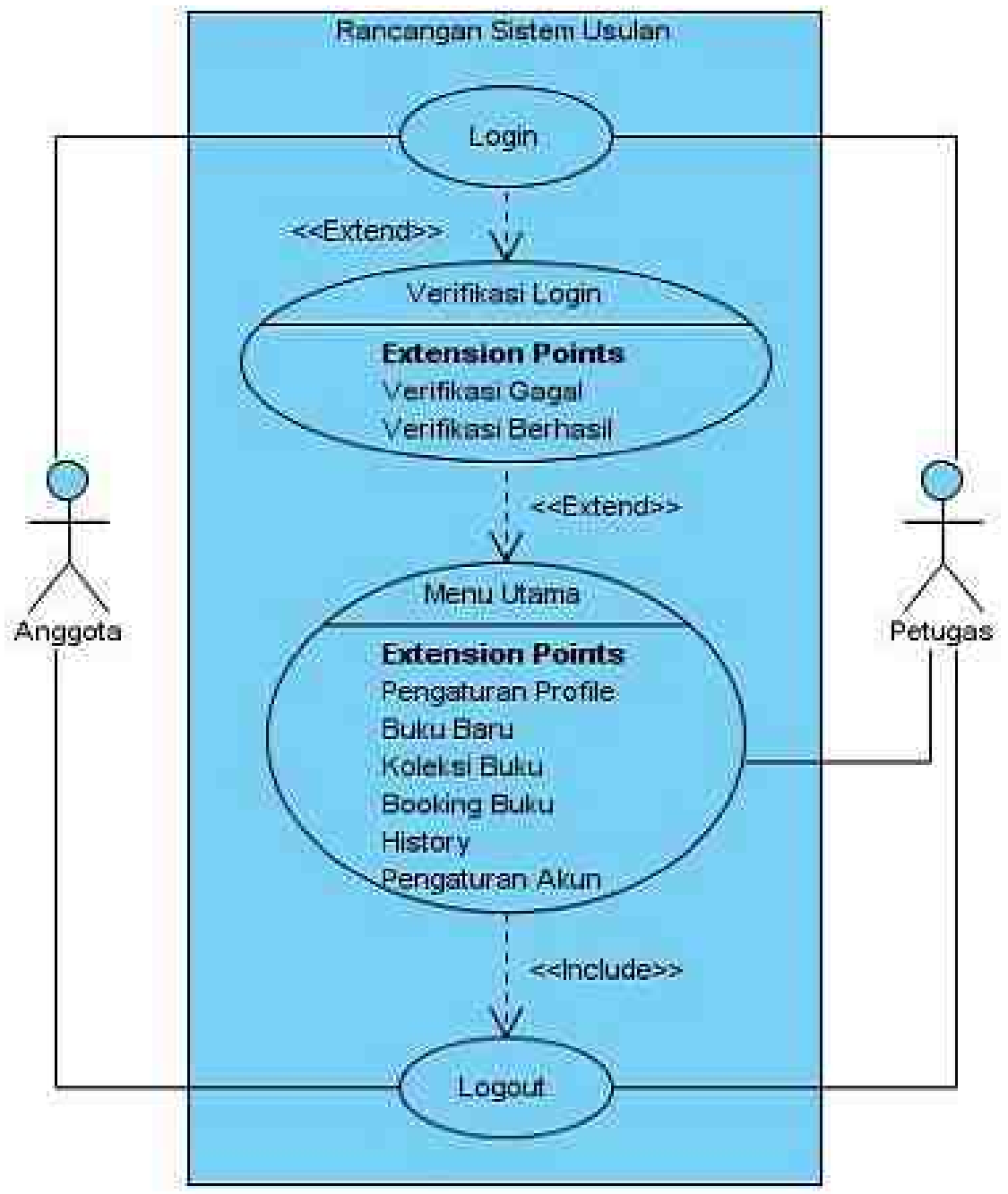

Gambar 1. Use Case Diagram

\section{Perancangan Basis Data (Database)}

Rancangan basis data pada sistem informasi booking buku berbasis web pada perpustakaan SMK Pancakarya Tangerang yang diusulkan ini digambarkan dengan menggunakan pemodelan UML yaitu class diagram. Selain itu, rancangan basis data ini juga berisi spesifikasi basis data yang telah dibuat. Berikut ini class diagram rancangan sistem yang dibuat. 


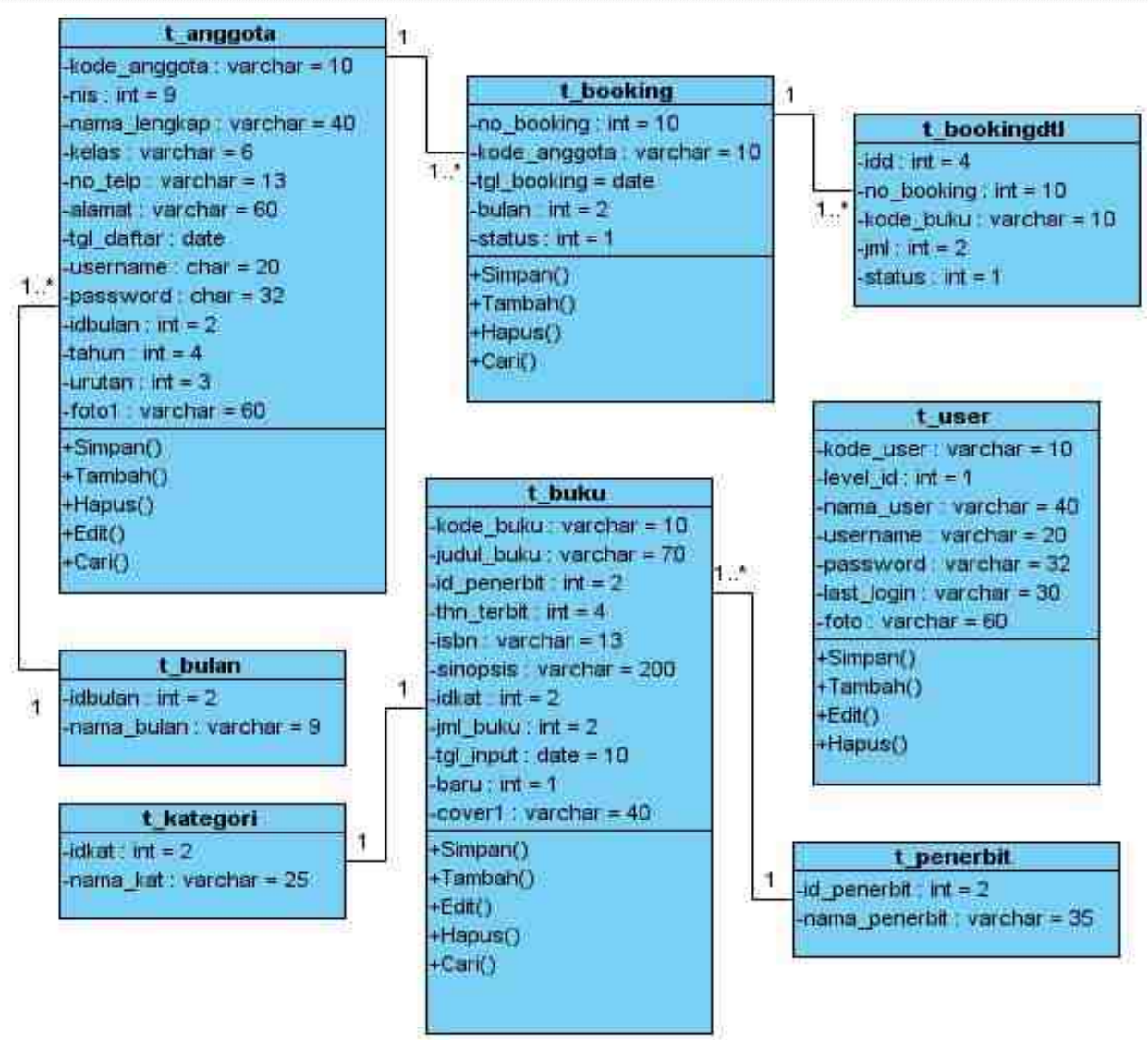

Gambar 2. Class Diagram

\section{Spesifikasi Basis Data (Database)}

Spesifikasi basis data merupakan sebuahdesign data yang telah di anggap normal. Design basis data menjelaskannama field,type data, size, dan keterangan field kunci. Berikut lampiran tabel spesifikasi basis data.

\section{Tabel 1. Tabel Anggota}

\begin{tabular}{|c|l|c|c|c|}
\hline No & \multicolumn{1}{|c|}{ Nama Field } & Type Data & Size & Keterangan \\
\hline 1 & kode_anggota & Int & 10 & Primary Key \\
\hline 2 & Nis & Int & 9 & - \\
\hline 3 & nama_lengkap & varchar & 40 & - \\
\hline 4 & Kelas & varchar & 6 & - \\
\hline 5 & no_tlp & varchar & 13 & - \\
\hline 6 & Alamat & varchar & 60 & - \\
\hline 7 & tgl_daftar & Date & 10 & - \\
\hline 8 & username & varchar & 20 & - \\
\hline 9 & password & varchar & 32 & - \\
\hline 10 & Idbulan & Int & 2 & - \\
\hline 11 & Tahun & Int & 4 & - \\
\hline 12 & urutan & Int & 3 & - \\
\hline 13 & foto1 & varchar & 60 & - \\
\hline
\end{tabular}


Tabel 2. Tabel Booking

\begin{tabular}{|c|l|c|c|c|}
\hline No & \multicolumn{1}{|c|}{ Nama Field } & Type Data & Size & Keterangan \\
\hline 1 & no_booking & int & 10 & $\begin{array}{c}\text { Primary } \\
\text { Key }\end{array}$ \\
\hline 2 & kode_anggota & int & 10 & $\begin{array}{c}\text { Foreign } \\
\text { Key }\end{array}$ \\
\hline 3 & tgl_booking & date & 10 & - \\
\hline 4 & Bulan & int & 2 & - \\
\hline 5 & status & int & 1 & - \\
\hline
\end{tabular}

Tabel 3. Tabel Booking Detail

\begin{tabular}{|c|l|c|c|c|}
\hline No & \multicolumn{1}{|c|}{ Nama Field } & Type Data & Size & Keterangan \\
\hline 1 & Idd & int & 4 & $\begin{array}{c}\text { Primary } \\
\text { Key }\end{array}$ \\
\hline 2 & no_booking & int & 10 & $\begin{array}{c}\text { Foreign } \\
\text { Key }\end{array}$ \\
\hline 3 & kode_buku & varchar & 10 & - \\
\hline 4 & jml & int & 2 & - \\
\hline 5 & status & int & 1 & - \\
\hline
\end{tabular}

Tabel 4. Tabel Buku

\begin{tabular}{|c|l|c|c|c|}
\hline No & \multicolumn{1}{|c|}{ Nama Field } & Type Data & Size & Keterangan \\
\hline 1 & kode_buku & varchar & 10 & $\begin{array}{c}\text { Primary } \\
\text { Key }\end{array}$ \\
\hline 2 & judul_buku & varchar & 70 & - \\
\hline 3 & id_penerbit & varchar & 35 & - \\
\hline 4 & thn_terbit & int & 4 & - \\
\hline 5 & Isbn & varchar & 13 & - \\
\hline 6 & sinopsis & varchar & 200 & - \\
\hline 7 & Idkat & int & 2 & $\begin{array}{c}\text { Foreign } \\
\text { Key }\end{array}$ \\
\hline 8 & jml_buku & int & 2 & - \\
\hline 9 & tgl_input & date & 10 & - \\
\hline 10 & Baru & int & 1 & - \\
\hline 11 & cover1 & varchar & 40 & - \\
\hline
\end{tabular}


Tabel 5. Tabel Penerbit

\begin{tabular}{|c|l|c|c|c|}
\hline No & Nama Field & $\begin{array}{c}\text { Type } \\
\text { Data }\end{array}$ & Size & Ket \\
\hline 1 & id_penerbit & int & 2 & Primary Key \\
\hline 2 & nama_penerbit & varchar & 35 & \\
\hline
\end{tabular}

Tabel 6. Tabel Bulan

\begin{tabular}{|c|l|c|c|c|}
\hline No & Nama Field & Type & Size & Ket \\
\hline 1 & idbulan & Int & 2 & Primary Key \\
\hline 2 & nama_bulan & varchar & 12 & - \\
\hline
\end{tabular}

Tabel 7. Tabel Kategori

\begin{tabular}{|c|c|c|c|c|}
\hline \multirow{2}{*}{ No } & Nama & Type & Size & Ket \\
& Field & Data & & \\
\hline 1 & idkat & int & 2 & Primary Key \\
\hline 2 & nama_kat & varchar & 40 & - \\
\hline
\end{tabular}

Tabel 8. Tabel User

\begin{tabular}{|c|l|c|c|c|}
\hline No & Nama Field & Type & Size & Ket \\
\hline 1 & kode_user & varchar & 10 & Primary Key \\
\hline 2 & level_id & int & 1 & - \\
\hline 3 & nama_user & varchar & 20 & \\
\hline 4 & username & varchar & 20 & - \\
\hline 5 & password & varchar & 32 & \\
\hline 6 & last_login & varchar & 30 & - \\
\hline 7 & foto & varchar & 60 & - \\
\hline
\end{tabular}




\section{IMPLEMENTASI}

\section{Tampilan Halaman Login}

Halaman login adalah halaman yang digunakan anggota perpustakaan untuk login. Jika akan login anggota perpustakaan harus memasukan username dan password.

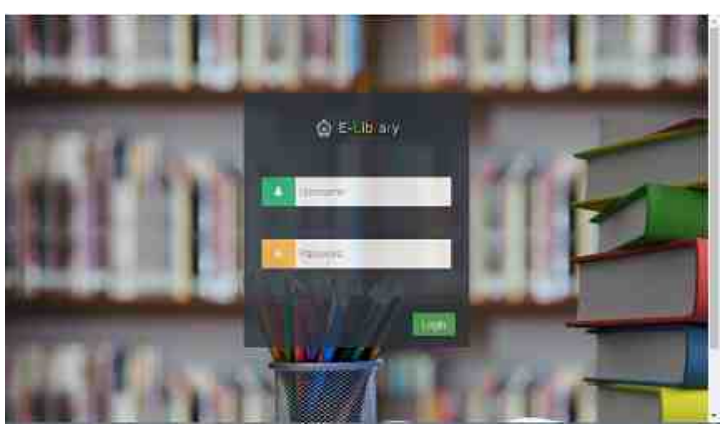

Gambar 3.Tampilan Halaman Login

\section{Tampilan Halaman Utama/Home}

Halaman utama/home merupakan tampilan awal setelah melakukan login.

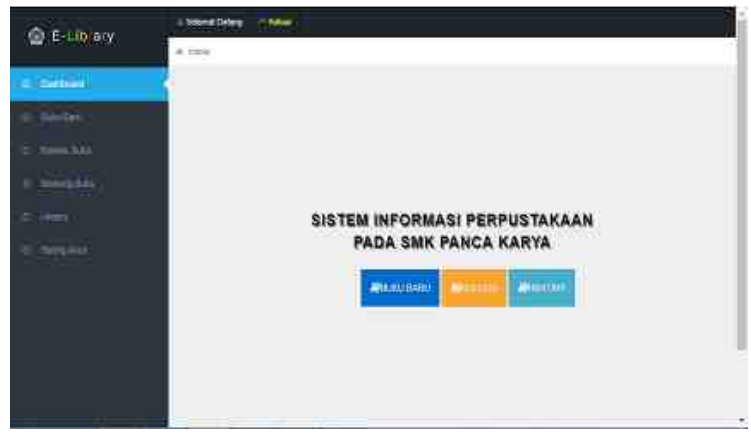

Gambar 4. Tampilan Halaman Utama/Home

\section{Tampilan Halaman Buku Baru}

Halaman Buku baru merupakan tampilan halaman yang berisi tentang informasi mengenai buku baru yang ada di perpustakaan.

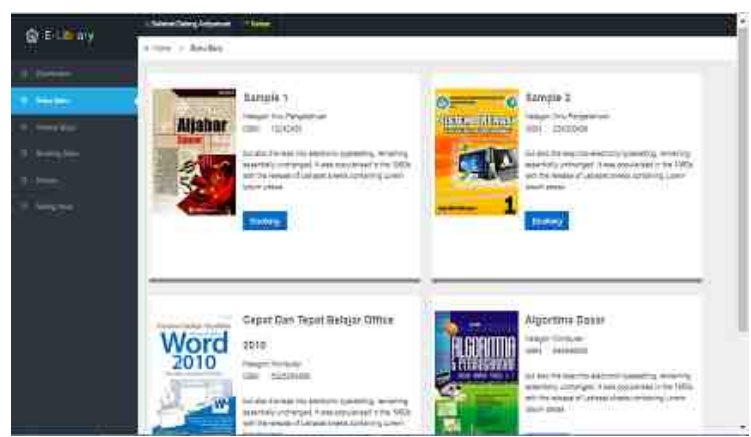

Gambar 5.Tampilan Halaman Buku Baru 


\section{Tampilan Halaman Koleksi Buku}

Halaman koleksi buku merupakan tampilan yang berisi tentang buku apa saja yang ada saat ini di perpustakaan.

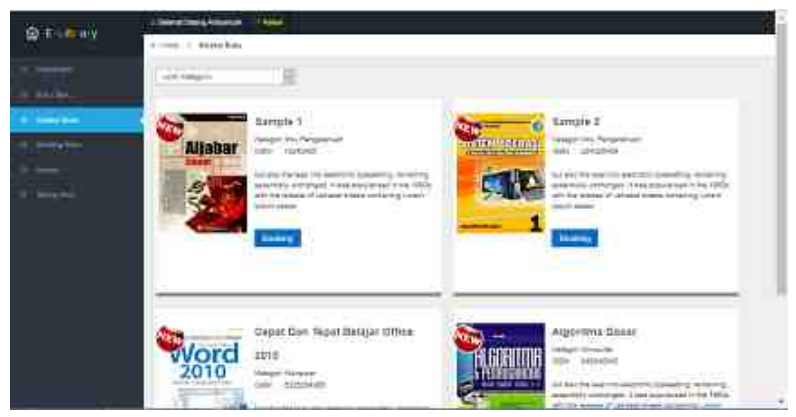

Gambar 6. Tampilan Halaman Koleksi Buku

\section{Tampilan Halaman Booking Buku}

Halaman Booking Buku yaitu halaman yang berisi tentang data buku baru maupun koleksi buku yang ada dan terdapat fasilitas untuk booking buku.

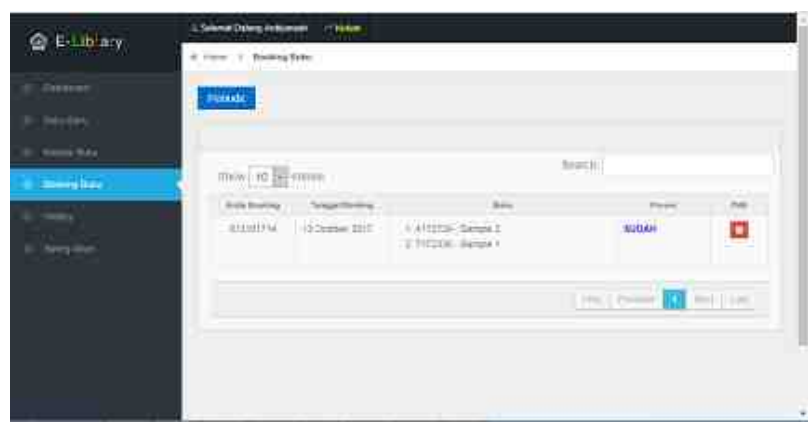

Gambar 7. Tampilan Halaman Booking Buku

\section{Tampilan Halaman History}

Halaman history adalah tampilan halaman yang berisi data buku yang sedang dipinjam dan yang sudah dikembalikan.

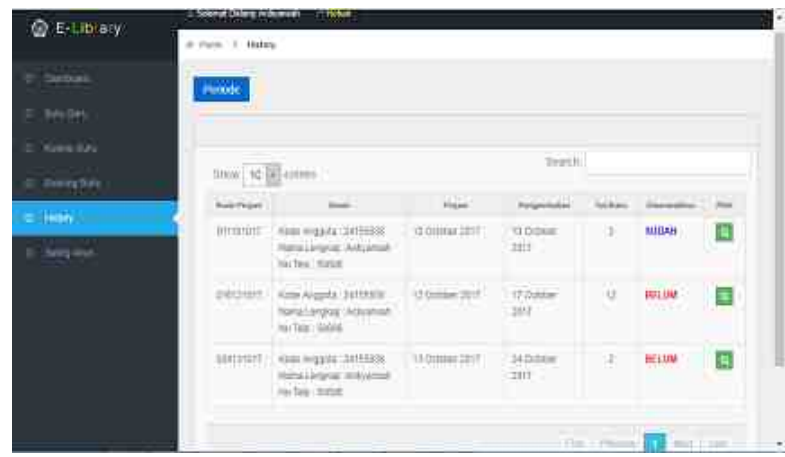

Gambar 8. Tampilan Halaman History 


\section{Tampilan Halaman Setting Akun}

Halaman setting akun adalah tampilan halaman yang berfungsi untuk mengatur akun yang terdiri dari username dan password.

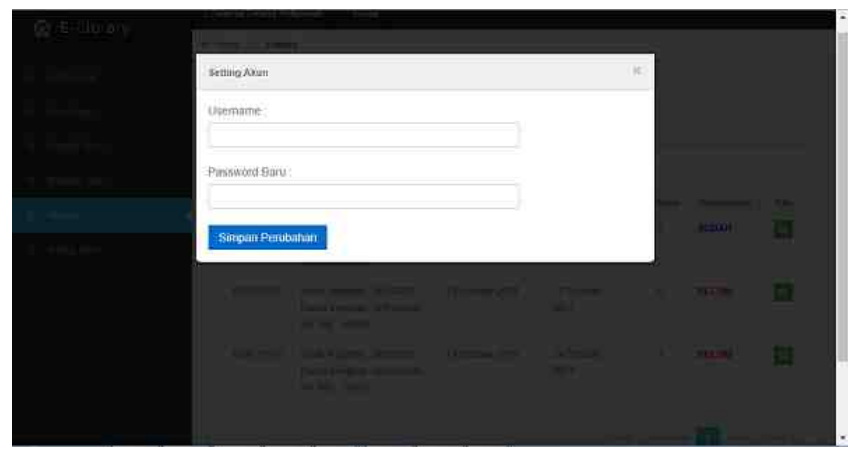

Gambar 9. Tampilan Halaman Setting Akun

\section{Tampilan Halaman Logout}

Halaman logout adalah tampilan halaman yang sama seperti logout. Jadi setelah logout akan kembali lagi untuk diminta login.

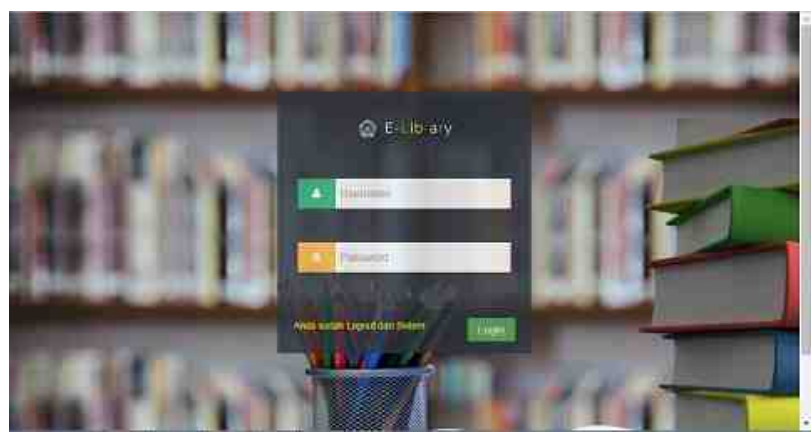

Gambar 10.Tampilan Halaman Logout

\section{KESIMPULAN DAN SARAN}

\section{KESIMPULAN}

Dengan memperhatikan beberapa hal yang telah dibahas diatas, dapat ditarik kesimpulan, sebagai berikut :

1. Sistem pelayanan yang berjalan saat ini pada perpustakaan SMK Pancakarya Tangerang masih bersifat manual.

2. Sistem yang berjalan saat ini masih belum efektif dan efesien dalam memenuhi kebutuhan sistem perpustakaan SMK Pancakarya.

3. Merancang sistem informasi perpustakaan berbasis web yang memudahkan anggota dalam mencari informasi tentang data buku dan melakukan peminjaman buku dengan cara booking buku terlebih dahulu. 


\section{SARAN}

Untuk meningkatkan atau memaksimalkan kualitas dari sistem informasi booking buku tersebut, maka disampaikan beberapa saran sebagai berikut :

1. Perlu diadakan training kepada para anggota yang akan menggunakan sistem, sehingga sistem tersebut dapat digunakan atau dimanfaatkan dengan sebaik mungkin.

2. Perlu adanya pengembangan yang lebih profesional terhadap sistem bagi para mahasiswa yang nantinya mengambil judul penelitian yang sama.

3. Perlu adanya suatu peningkatan kualitas, dengan memberikan informasi yang up to date dan mengembangkan sistem yang bersifat digital.

\section{DAFTAR PUSTAKA}

[1] A. D. Ross \&W. Jon P, 2015. "A Definition of Systems Thinking: A Systems Approach-Procedia Computer Science”, International Journal Conference on Enterprise Information System. USA, 2015.

[2] S. Azhar, Sistem Informasi Manajemen: Konsep dan Pengembangan Secara Terpadu. Bandung: Lingga Jaya, 2017.

[3] H. Agus Umar, Pemodelan Sistem Informasi Administrasi Proyek Desain Interior Studi Kasus: PT Wang Interior Jakarta, Jurnal Sistem Informasi. Jakarta Selatan, Vol.5 No.3, 2015.

[4] M. Siti dan M. Sabilal, Sistem Manajemen Perpustakaan (Online) Pada SMP "Empat Lima” 2 Kedungpring Lamongan. Jurnal Teknika. Lamongan, Vol.6 No.1, 2014.

[5] W. Ary Budi, Y. Muhammad, dan M. Moh. Iqbal Awi, Perancangan Sis+ Menggunakan Metode YII Framework Pada Perguruan Tinggi Raharja, Jurnal CCIT. Tangerang, Vol.8 No.2, 2015.

[6] I. Indra Griha Tofik dan H. George Pri, Perancangan Aplikasi Koperasi Simpan Pinjam Berbasis Web (Studi Kasus Koperasi Mitra Setia), Jurnal Ilmiah Ekonomi. Sukabumi, Vol. 5 Edisi. 10, 2017.

[7] W. Kusumaningati Sulistya, Pengembangan Sistem Informasi Kartu Menuju Sehat Sebagai Alternatif Pengelolaan Posyandu Secara Digital, Laporan Tugas Akhir Skripsi. Yogyakarta, 2014.

[8] S. Novita dan N. Rice, Sisttem Informasi Penjualan Pupuk Berbasis E-Commerce, Jurnal TEKNOIF. Pekanbaru, Vol.3 No.2, 2015.

[9] B. Febrian Aulia, Perancangan Website Pada PT Ratu Enim Palembang, Jurnal REINTEK. Medan, Vol.7 No.1, 2012.

[10] H. Miwan Kurniawan dan P. Alfin, Perancangan Sistem Informasi Perpustakaan Online Pada SMK Negeri 9 Kota Bekasi, Jurnal Simposium Nasional Ilmu Pengetahuan dan Teknologi (SIMNASIPTEK). Bekasi: AMIK BSI, 2015.

[11] B. Azza Abidatin, Sistem Informasi Pengolahan Data Tabungan Siswa MI Bahrul Ulum Berbasis Web Mobile Menggunakan Codeigniter dan Bootstrap, Jurnal Teknika. Lamongan, Vol.8 No.2. ISSN: 2085-0859, 2016.

[12] H. Priyanto, dan K. Jauhari Khairul, Pemrograman WEB, Bandung: Informatika, 2015.

[13] R. H. A. dan I. Moch, Sistem Informasi Manajemen, Bandung: CV Pustaka Setia, 2016. 